\title{
Genetic Relationship and Structural Analysis of Resident Pacific Salmon Oncorhynchus Masou in Mijiang River, China
}

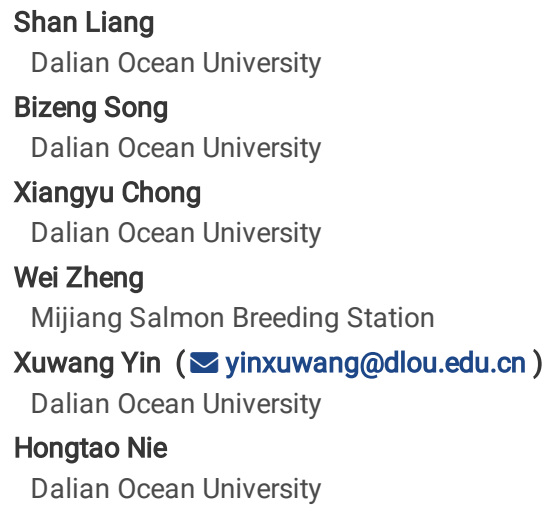




\section{Abstract}

Masu salmon Oncorhynchus masou has been listed as national second-class protected species in China, and many of its local populations have been under threats of decline because of environmental deterioration by human activity, such as habitat loss, water pollution, or dams. Genetic characteristics should be clarified in wild masu salmon population for an effective protection and recovery. In the present study, we explained genetic relationship and structure of masu salmon population in Mijaing River by sequencing the COI gene and analyzing microsatellite makers. Results of COI sequences analysis revealed 15 gene variable sites in approximately $696 \mathrm{bp}$, which defined 12 haplotypes, including some haplotypes related to geographic regions. The NJ tree indicated genetic relationship that we preliminarily inferred, that is, the masu salmon from Mijiang River belonged to the cherry salmon family ( $O$. masoumasou). Results based on 14 microsatellite loci showed high haplotype diversity and low nucleotide diversity, indicating low genetic diversity of wild masu population in Mijaing River. The observed genetic structure was influenced primarily by bottlenecks due to overfishing and habitat loss. Since masu salmon has become highly vulnerable in China, we recommend to strengthen the protection of resident masu salmon population.

\section{Introduction}

Masu salmon (Oncorhynchus masou) is endemic to the Far East, and it is an economically important fish species over the world ${ }^{1}$. Similar to other salmonids, masu salmon exhibits two life history patterns: anadromous and resident forms ${ }^{1}$. Some individuals called anadromous upstream migration in spring, spawn in autumn, and die shortly after spawning, while the others named resident remains in the river alive and reproduce ${ }^{2-4}$. Most females migrate to the ocean following parr-smolt transformation, which occurs in at least one year-old females, while approximately $80 \%$ of male remain alive and complete sexual maturation in their natal river ${ }^{1}$. Anadromous masu salmon has an economical value because of their taste and quality, and the resident masu salmon is commercially important for providing recreational angling opportunities ${ }^{5}$. The importance of masu salmon has been long recognized, because it is the only species of Pacific salmon which is differentiated into subspecies, and the intraspecific differentiation of masu salmon is rather complex $1,6,7$. Masu salmon can be classified into four subspecies ${ }^{8,9}$, including Oncorhynchus masou ishikawae (Satsukimasu salmon), masou masou (Cherry salmon) , O. masou subsp. (Biwa salmon), and O. masou formosanus (Formosa landlocked salmon). The geographic distribution of these four subspecies remarkably differs. Satsukimasu salmon is distributed in southwestern Japan, whereas cherry salmon inhabits over all Japanese Islands, except for the southwestern area. Biwa salmon is solely distributed in Lake Biwa and the rivers entering the lake ${ }^{10,11}$. Formosa landlocked salmon is endemic to Taiwan ${ }^{11}$. However, in recent years, the local populations declined rapidly, and the diversity of species decreased gradually because of habitat destruction by pollution, dams, and human activity ${ }^{12-15}$. Moreover, considering that this species reproduces only once in its lifetime, masu salmon has become highly vulnerable in some areas ${ }^{16,17}$. For the enhancement of fishery production and protection of germplasm resources, propagation and artificial release of masu salmon have been carried out throughout the world ${ }^{18}$. However, the artificial releases of domesticated fish a serious problem for both conservation and fisheries management, because it frequently alters the genetic characteristics and reduces the genetic heterogeneity among wild salmon populations ${ }^{19-22}$. For example, Kawamura found that stocking hatchery fish greatly changes the genetic characteristics of the indigenous population of Satsukimasu salmon in the River Koza, and the genetic diversity of isolated wild populations have declined markedly ${ }^{14}$.

Genetic diversity is important for the long-term survival of natural populations, because it confers the ability to adapt to changing environmental conditions, thereby increasing their fitness ${ }^{23-25}$. Therefore, the indigenous genetic structure of local masu salmon population should be clarified to effectively maintain and conserve genetic diversity. In the 1860s, Japan developed the residency population into an artificial breeding species (O. masou masou). China introduced this species in 1996 and carried out a series of studies ${ }^{26}$. The number of masu salmon in China reached hundreds of thousands in the 1900 s, but dropped dramatically to 200-300 because of overfishing in the 1950s. Mijiang River is one of the few areas where resident masu salmon inhabits in China. At present, the anadromous population has basically disappeared in the Mijiang River, while the resident population is also in an endangered state ${ }^{27}$. To maintain the continuation of the masu salmon population, artificially reproduced and released has been implement in China. This behavior delivered an apparent effect, but it has not restored the population to the 1900s. To date, a few studies about genetic structure on masu salmon have been carried out in China, but the genetic diversity remains unclear. Accordingly, we inferred and analyzed the genetic relationship and structure of masu salmon in Mijiang River.

We investigated the genetic diversity and population structure of wild masu salmon populations collected from Mijiang River by using the COI gene, determined phylogenetic relationships of haplotypes, and evaluated the genetic differentiation. We also analyzed 14 microsatellite loci to assess genetic diversity and characterize the genetic structure of masu salmon populations. More specifically, we tested the following hypothesis: (1) The masu salmon population of Mijiang River is the same subspecies as the cherry salmon in Japan; and (2) The genetic diversity of the masu salmon population in Mijiang River is low.

\section{Results}

\section{Extemal Characteristics}

The body length, fork length, body weight (total and without internal organs), sex ratio, and age composition of two masu salmon groups are summarized in Table 2. The proportion of females is $11 \%$ in Mijiang salmon (hereafter MJ salmon) and $75 \%$ in farmed cherry salmon (hereafter JP salmon). In the two masu salmon groups, 2-year-old fishes are the main components, accounting for $40 \%$ and $50 \%$ for MJ and JP salmon, respectively. The farmed salmon had a body length of $16.46 \pm 0.52 \mathrm{~cm}$, fork length of $15.19 \pm 0.52 \mathrm{~cm}$, head length of $3.56 \pm 0.12 \mathrm{~cm}$, total body weight of $49.51 \pm 7.25 \mathrm{~g}$ and weight of $41.47 \pm 5.68 \mathrm{~g}$ excluding internal organs. The C.D values of the 11 proportional traits are shown in Table 3. Only in Bd / SI and CPI / SI, the C.D values were 1.658 and 2.902, were greater than 1.28. The C.D values between the other proportional traits were all less than 1.28 . 


\section{Col variation in masu salmon}

COI gene consists of $23.5 \% \mathrm{~A}, 31.8 \% \mathrm{~T}, 17.9 \% \mathrm{G}$, and $26.7 \% \mathrm{C}$ in $\mathrm{MJ}$ salmon. The average content of $\mathrm{A}+\mathrm{T}$ is higher than $\mathrm{G}+\mathrm{C}$. The content of $\mathrm{G}$ is the lowest, showing an obvious anti-G bias, which is consistent with the characteristics of vertebrate mitochondrial DNA. The DNA sequencing of COI detected 15 variable sites, including 13 synonymous and 2 non-synonymous substitutions (Table 4). MJ salmon detected five variable sites (4 synonymous and 1 nonsynonymous substitution), which differ in the 170 and 299 nucleotide positions. The non-synonymous substitution in the 562 nucleotide position was performed in all salmon subspecies, while the mutation in the 325 nucleotide position only existed in biwa salmon. In addition, the unique variable site of satsukimasu salmon and Formosa landlocked salmon are in 185 and 599 positions, respectively. In the population of MJ salmon, two special variable sites were observed in 674 and 299 nucleotide positions.

Twelve haplotypes were defined as "a" to "I" from the 64 individual sequences, including five haplotypes from MJ salmon, three haplotypes from cherry salmon, two haplotypes each from satsukimasu salmon and biwa salmon, and one haplotype from formosa landlocked salmon. Especially, MJ and cherry salmon had an identical haplotype "b", and 11 other haplotypes were obtained from a single population. The distribution of most haplotypes has obvious geographic characteristics. Haplotypes "a" and "c" were only observed in cherry salmon from Japan, while haplotypes " $f$ " and " $g$ " were observed in biwa salmon from Biwa Lake. Haplotype "e" is the sole haplotype in formosa landlocked salmon, and haplotypes "i" to "I" from MJ salmon is unique. In a network (Fig. 1), haplotype "b" located in the central. Only the haplotypes of biwa salmon separate from "b" clearly, while those of the remaining masu salmon subspecies intermingle with each other.

Haplotype diversity $(H d)$ and nucleotide diversity $(\pi)$ are important indicators for evaluating population genetic diversity; the higher the value, the richer the population genetic diversity. In MJ salmon, $H d$ was remarkably high with a value of $0.817 \pm 0.025$. We used the JP salmon for comparison, yielding a $H d$ value if $0.268 \pm 0.113$. The $\pi$ value of MJ salmon was $(0.00243 \pm 0.00022)$ was at a low level (Table 5$)$.

Genetic distances among the 12 haplotypes were obtained with their standard deviations (Table 6) by using the Kimura's two parameter method ${ }^{28}$. The genetic distances of haplotype "b" between MJ and JP salmon was 0.0000 . The inter-group genetic distance ranged from 0.0016 to 0.0095 between MJ and cherry salmon and from 0.0000 to 0.0063 between MJ and JP salmon. In addition, we found that the intra-subspecies variations (from 0.0016 to 0.0063 ) in MJ salmon was nearly equal to the inter-group genetic distance. The genetic distances of only biwa salmon were significantly isolated, with values $0.0063-$ 0.0128 in MJ salmon, $0.0048-0.0127$ in cherry salmon, and $0.0063-0.0095$ in JP salmon.

The base saturation analysis of $\mathrm{COI}$ sequence is shown in Figure 2. A linear relationship was observed between $T s$, $T V$, and F84 distance, indicating that the base transformation and transversion of $\mathrm{COI}$ sequence did not reach saturation during genetic evolution, and this information could be used for phylogenetic analysis. To draw a neighbor-joining tree from $\mathrm{COI}$ gene, we included the sequence for O. mykiss as an outgroup for the 0 . masou complex (Fig. 3). Biwa salmon, satsukimasu salmon, and formosa landlocked salmon were separated, while MJ, JP, and cherry salmon were shown in the same branch after 1,000 bootstrap replicates.

\section{Microsatellite variation in masu salmon}

All the 14 loci were highly polymorphic in the Mijiang population examined without linkage disequilibrium ( $L D$ ) between loci. Table 7 summarizes the number of alleles, allelic richness $(A r)$, and the observed $(h o)$ and expected heterozygosity (he) per population of 14 microsatellite loci. Overall, 186 alleles were found in the population. The mean allelic richness among all loci within populations was 9.38 in the MJ salmon populations. The number of alleles in MJ salmon was 11.0714 . The observed heterozygosity was 0.6061 , while the expected heterozygosity was 0.7863 . Overall, the mean expected heterozygosity was slightly higher than the observed heterozygosity. Nine loci in population MJ showed a significant deviation from Hardy-Weinberg equilibrium (HWE), as determined using GENEPOP. In addition, tests for $L D$ suggested no significant linkages in the Mijiang population. The mode shift indicator showed a normal $L$-shaped distribution, thus explaining the genetic bottlenecks in Mijiang population.

AMOVA with both markers (Table 8) revealed the population structure in masu salmon that the variation within populations (COI, $39.0 \%, \mathrm{P}<0.001$; microsatellites, $61.0 \%, \mathrm{P}<0.001)$ was significantly higher than that among populations $(\mathrm{COI}, 2.5 \%, \mathrm{p}=0.000$; microsatellites, $97.5 \%, \mathrm{P}<0.001)$, indicating the congruence of both mitochondrial and microsatellite markers in estimating the genetic structure of masu salmon.

The $F_{I S} F_{S T}$, and $N m$ values in masu salmon based on microsatellites are summarized in Table 9 . The $F_{S T}$ value is 0.0540 in the intra-group of MJ salmon and -0.0232 in the intra-group of JP salmon. The value of $\mathrm{F}_{\mathrm{IS}}$ was similar in two populations $(0.1995$ and 0.2294$)$. Otherwise, the pairwise $F_{S T}$ were estimated as $0.375(P<0.01)$ and $0.024(P<0.01)$ between MJ and JP salmon for COI and microsatellite markers in Table 10, respectively (although COI was larger than for microsatellites). Nm values are responsible for gene flow with a value of 10.595 in MJ salmon. Nm and $F_{S T}$ values are inversely proportional.

\section{Discussion}

In previous studies, the biwa salmon was separated from the masu subspecies complex ${ }^{29}$. However, the masu salmon which distributed in the Mijiang River of China has not been clearly defined. In the present paper, we explored the genetic relationship of the masu salmon from Mijiang River.

Among the 11 proportional traits of C.D value, nine traits were lower than 1.28. According to Mayr's 75 percent rule, if the C.D is greater than 1.28 , the morphological characteristics between the two populations have reached the differentiation level of the subspecies ${ }^{30}$. A value less than 1.28 indicates a normal intraspecies level difference. However, this subspecies identification method lacks consideration in the biological and biogeographical factors. Hence, further analysis is required from the genetics. 
Twelve haplotypes ("a" to "I") were detected in 64 individuals. MJ, JP, and cherry salmon share the same haplotype "b". The haplotypes are mostly region specific, suggesting their recent appearance and rapid expansion ${ }^{25}$. This may be due to the increase in masu salmon population by artificial release. According to the network (Fig.3), haplotype "b" might be ancestral, and other haplotypes diverge from haplotype b. In addition, the genetic distance of haplotype "b" was 0.000 between MJ and JP salmon and 0.0016 between MJ and cherry salmon. This finding was obtained possibly because part of cultivation cherry salmon escaped from farms to Mijiang River, when a flood occurred in this farm several years ago (Farm records). From the perspective of the evolutionary tree, these three groups (MJ salmon, JP salmon and cherry salmon) are clearly located in the same branch, which shows the same result as the haplotype network. Notably, the genetic distance between $\mathrm{MJ}$ and cherry salmon is as small as the variations within MJ or cherry salmon. This finding is consistent with the results of previous studies by Ichiro Oohara et al ${ }^{29}$.

The microsatellites showed tiny genetic differentiation between these two populations. However, a certain genetic differentiation is present between the Mijiang population and other populations. Whether this differentiation can reach the level of subspecies needs further confirmation. Populations distributed in different regions have undergone certain changes in morphological structure or physiological functions because of the effect of their living environment and are classified as subspecies ${ }^{31}$. In previous studies, cherry salmon were artificially introduced into the river that flows into Biwa Lake in $1970{ }^{32}$. Biwa salmon was separated from the masu subspecies complex, because they showed significant differences on the evolutionary tree and the spots on the side of the body are different ${ }^{29}$. To obtain further evidence of defining the wild salmon from Mijiang River, researchers should increase the experimental samples of both masu salmon in Mijiang River and cherry salmon should, not only for COI gene, but for further genetic analysis of the entire mitochondrial gene. However, when a population lives in different geographical areas for a long time, whether they can also evolve into new subspecies, similar to biwa salmon separated from cherry salmon, poses a problem ${ }^{29}$

Five haplotypes were detected in the COI gene sequence of the masu salmon from Mijiang, the haplotype diversity $(0.817 \pm 0.025)$ was greater than 0.500 , which performed a high level. For nucleotide diversity, both two populations show a low level $(<0.005)$. The masu salmon population in Mijiang River has high haplotype diversity and low nucleotide diversity, indicating and rapid growth and mutation accumulation after the population bottleneck, rapid population growth enhanced the retention of new mutations ${ }^{33-35}$. Our $\mathrm{COI}$ and microsatellite analyses provided congruent estimates among the two levels of the population hierarchy, in which the genetic variation within populations is the main source of population genetic variation (Although the extent of variance was always larger for $\mathrm{COI}$ than for microsatellites). The cumulative amounts of mutations in microsatellites are higher than those in mitochondria, in which the differential mutation rates between the two markers result in higher accumulation of homoplasic mutations in microsatellite DNA than in mitochondrial DNA ${ }^{25}$. The larger within-population than among-population variation suggests low effects of geographical distance on limiting gene flow. Nm values are responsible for gene flow, and the higher the gene flow, the lower the differentiation between populations. When Nm>4, the groups mate randomly.

Among the 14 microsatellite loci in the Mijiang population, nine loci were consistent with the Hardy-Weinberg equilibrium, confirming that masu salmon population underwent random mating. The deviations from the Hardy-Weinberg equilibrium for some loci indicate heterozygote deficiency (the Wahlund effect). In addition, the observed heterozygosity is greater than the expected heterozygosity, and the inbreeding coefficient FIS is positive, indicating that inbreeding occurred in the population.

According to the results of the bottleneck, the allele frequency distribution of masu salmon in Mijiang showed an L-shaped structure, indicating that the population experienced a genetic bottleneck. Biological genetic bottleneck refers to a population's rapid decline in population because of environmental disasters or human overhunting in a certain period, which leads to a decline in the quality of the population's gene pool. Many endangered species in the world have experienced genetic bottlenecks (ie. O.masou ishikawae). If the number of the population cannot be recovered effectively in time, the quality of its gene pool will be rapidly reduced because of genetic drift or even extinction ${ }^{14}$. The water in the Mijiang River is clear and has been the home for salmons. However, two dams were built on the Mijiang River, thus preventing masu salmon migration and making it difficult to reach the spawning and breeding grounds in the last century. In addition, the economic development and utilization of Dahuanggou, seasonal drifting, and human overfishing resulted the sharply decline in masu salmon population ${ }^{36}$. The masu salmon has low genetic diversity possibly because of the genetic bottlenecks following damming and environmental deterioration.

In conclusion, we temporarily recognized the masu salmon from Mijiang River as cherry salmon. We also revealed a low level of genetic diversity in masu salmon population. In addition, the population genetic structure of masu salmon shows a genetic bottleneck. Under the current situations, a scientific protection system and restore genetic diversity should be established for the conservation of indigenous masu salmon populations in Mijiang River.

\section{Methods}

\section{Statement confirming}

All of the experiments were conducted in accordance with the guidelines and regulations of the Animal Research and Ethics Committee of Dalian Ocean University and complied with China's existing laws and regulations on biological research. All experimental protocols were approved by ethics committee.

\section{Sample Collections}

A total of 35 individuals of masu salmonwere captured by electrofishing in the Mijiang river on July 2020 . All samples were preserved at $-80{ }^{\circ} \mathrm{C}$ until a part of muscle clipped and extracted the DNA extraction.

\section{Morphological Analysis}


Each individual was measured and recorded, the body weight was measured by an electronic balance (standard weight in micrograms), and the body length $(\mathrm{BI})$, body depth $(\mathrm{Bd})$, fork length $(\mathrm{FI})$, head length $(\mathrm{HI})$, body width $(\mathrm{Hw})$, standard length $(\mathrm{SI})$, snout length (SNI), eye diameter (Ed), head length behind eye $(\mathrm{HEI})$, body length before anal (BAI), caudal peduncle length (CPI) and caudal peduncle depth (CPd) were measured using a ruler (standard length in micrometer). SPSS 26.0 was used to calculate the standard deviation of the results of morphological features, followed by Student's $t$ test. SI was used for standardization to eliminate the influence of body size. According to Mayr's difference coefficient formula C.D $=(M 1-M 2) /(S 1+S 2)$ and the subspecies classification standard of C.D $\geq 1.28^{30}, 11$ proportional traits were calculated. The sex of the sample was determined based on gonads. Ten scales (between the lateral line and below the dorsal fin) were cleaned to identify the age under a digital imaging microscope.

\section{Col Analysis}

Individual DNA was extracted from the muscle by using the TIANamp Marine Animals DNA kit. (Tiangen Biotech, Beijing, China). The COI gene was amplified by polymerase chain reaction (PCR) by using the primers COI-F (5'-TCAACCAACCACAAAGACATTGGCAC-3') and COI-R (5'-

TAGACTTCTGGGTGGCCAAAGAATCA -3'). Primers were designed by Sangon Biotech (Shanghai, China) Co., Ltd. The thermal cycling program for the PCR consisted of an initial denaturation at $95^{\circ} \mathrm{C}$ for $5 \mathrm{~min}$, followed by 38 cycles of denaturation at $94^{\circ} \mathrm{C}$ for $30 \mathrm{~s}$, annealing at $58{ }^{\circ} \mathrm{C}$ for $30 \mathrm{~s}$, and extension at 72 ${ }^{\circ} \mathrm{C}$ for $60 \mathrm{~s}$. The amplification was followed by a 10 minutes final $10 \mathrm{~min}$ of final extension at $72{ }^{\circ} \mathrm{C}$. The amplified PCR products were resolved by electrophoresis on $1 \%$ agarose gels and purified with a SanPrep columnar PCR product purification kit (Sangon Biotech, Shanghai, China). The PCR product was sequenced using a $3730 \mathrm{xl}$ genetic analyzer (ABI, USA). The DNA sequences ofmasu salmon have been submitted to GenBank databases under the accession numbers MZ971115- MZ971167.

\section{Microsatellite Analysis}

The 14 microsatellite loci derived from masu salmon ${ }^{37-40}$ were analyzed for collected samples (Table 1). The thermal cycling program for the PCR consisted of an initial denaturation at $95^{\circ} \mathrm{C}$ for $3 \mathrm{~min}$, followed by 10 cycles of denaturation at $94{ }^{\circ} \mathrm{C}$ for $30 \mathrm{~s}$, annealing at $60{ }^{\circ} \mathrm{C}$ for $30 \mathrm{~s}$, and extension at $72{ }^{\circ} \mathrm{C}$ for 30 s. These processes were then followed by 35 cycles of denaturation at $94^{\circ} \mathrm{C}$ for $30 \mathrm{~s}$, annealing at $55^{\circ} \mathrm{C}$ for $30 \mathrm{~s}$, and extension at $72{ }^{\circ} \mathrm{C}$ for $30 \mathrm{~s}$. The amplification was followed by a $5-8 \mathrm{~min}$ final extension at $72{ }^{\circ} \mathrm{C}$. PCR was performed in a $32 \mu \mathrm{l}$ reaction volumes containing $1 \mu \mathrm{l}$ of genomic DNA, $1 \mu \mathrm{l}$ of each primer, $1 \mu \mathrm{l}$ of dNTP, $0.5 \mu \mathrm{l}$ of Taq polymerase, and $2.5 \mu \mathrm{l}$ of $10 \mathrm{X}$ reaction buffer (with $\mathrm{MgCl} 2$ ). The size of fluorescence-labeled allele fragments was measured on a 3730xl genetic analyzer, and then analyzed with Gene Mapper version 4.1.

\section{Data analysis}

A multiple alignment of $\mathrm{COI}$ sequences was aligned by ClustalW to identify variable nucleotide positions and synonymous or non-synonymous codon positions by Mega 7.0. DNAsp 6.0 (available at http://www.ub.es/dnasp) was used to defined haplotypes.

To effectively understand the phylogenetic relationships among $O$. masou species in a wider range, we downloaded nine COI genes sequences of $O$. masouishikawae, O. masoumasou, O. masou subsp. and O. masouformosanus, were from GenBank (accession nosare showed in Fig.3) and integrated them in our analyses. Genetic distance matrix was analyzed using MEGA 7.0. DAMBE 7.0.35 was used to determine whether the molecular data is suitable for the analysis of the phylogenetic tree, $T_{S}$ and $T_{V}$ were considered as the vertical axis, and F84 distance was considered as the horizontal axis. A neighbor-joining tree was constructed using MEGA 7.0, and 1,000 bootstrap replicates were set for the analysis to obtain confident supports. The haplotype network was constructed for each subspecies by using median-joining method as implemented in Network 10.2. To understand the population structure, haplotype diversity and nucleotide diversity were calculated using the software DNASP 6.0. The hierarchical nesting of genetic diversity was estimated by analyzing the molecular variance implemented in ARLEQUIN.

The values of the Hardy-Weinberg equilibrium (HWE), linkage disequilibrium (LD), pairwise $F_{S T}$ values, and the number of alleles per locus (NA) were

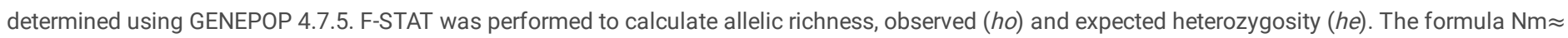
$\left(1-F_{S T}\right) / 2 F_{S T}$ was used to calculate the gene flow between groups. The program BOTTLENECK version 1.2.02 was used to test for heterozygosity excess to determine if allele distributions within populations were affected by recent changes in population size.

\section{Declarations}

\section{Acknowledgments}

This study was supported by the National Natural Science Foundation of China (41977193), and the National Science and Technology Basic Resources Survey Program of China (2019FY101704区

\section{Author Contributions}

X.Yin and W.Zheng conceived this study; S.Liang, B.Song and X.Chong designed and performed this experiments; W.Zheng provided the samples; X.Yin and H.Nei guided the experiment; S.Liang and X.Chong analysed the date. S.Liang prepared figures and tables and wrote the manuscript. All of the authors reviewed and approved the manuscript.

\section{Additional Information}

Competing financial interests: The authors declare no competing financial interests. 


\section{References}

1. Kato, F. Life history of masu salmon and amago salmon (Oncorhynchus masou and Oncorhynchus rhodurus). University of British Columbia Press (1991).

2. B., Jonsson, J., H. \& L'Abée-Lund. Latitudinal clines in life-history variables of anadromous brown trout in Europe. Journal of Fish Biology 43, 1-16 (1993).

3. Ferguson, A., Reed, T. E., Cross, T. F., McGinnity, P. \& Prodöhl, P. A. Anadromy, potamodromy and residency in brown trout Salmo trutta : the role of genes and the environment. Journal of Fish Biology 95 (2019).

4. Kuroki, M., Tamate, T. \& Morita, K. An additional life-history tactic of masu salmon: Migration of parr to coastal habitats. Ecology of Freshwater Fish 29, 495-501, doi:10.1111/eff.12544 (2020).

5. Yu, J.-N. et al. New polymorphic microsatellite markers for the masu salmon (Oncorhynchus masou masou) from Korea and their application to wild and hatchery populations. Biochemical Systematics and Ecology 61, 260-267, doi:10.1016/j.bse.2015.06.019 (2015).

6. Hanamura, N. Salmon of the North Pacific Ocean-Part III. A review of the life history of North Pacific salmon: Sockeye salmon in the far east. Int.north Pac.fish.comm.bull (1966).

7. Zhivotovsky, L. A. et al. Genetic differentiation and the problems of conservation of masu salmon (Oncorhynchus masou Brevoort, 1856 (Pisces: Salmonidae)) populations. Russian Journal of Marine Biology 43, 83-91, doi:10.1134/s1063074017010138 (2017).

8. Fujioka \& Yasuhiro. Morphological, physiological and ecological study on Biwa salmon - II. Morphological changes associated with growth and parr-smolt transformation in Biwa salmon Oncorhynchus rhodurus and Amago salmon Oncorhynchus rhodurus. Nsugaf 54, 77-86, doi:10.2331/suisan.54.77 (1988).

9. Kato, F. A note on the scientific name and phylozeny of the amago salmon. Bull Fukui Mun Mus Nat His 32, 47-54 (1985).

10. Kato, F. On the sea-run form of Oncorhynchus rhodurus obtained in Ise Bay. Japanese Journal of Ichthyology 20 (1973).

11. Okabe, T. et al. Genetic and Morphological Characteristics in the Local Population of the Landlocked Salmon Oncorhynchus masou Originally Distributed in Kanagawa Prefecture, Japan. Mar Biotechnol (NY) 22, 812-823, doi:10.1007/s10126-020-09975-2 (2020).

12. Hart, D. \& Leroy, P. N. A Special Section on Dam Removal and River Restoration. Bioscience, 653-655 (2002).

13. Fukushima, M., Kameyama, S., Kaneko, M., Nakao, K. \& Steel, E. Modelling the effects of dams on freshwater fish distributions in Hokkaido, Japan. Freshwater Biology 52, 1511-1524 (2010).

14. Kawamura, K., Kubota, M., Furukawa, M. \& Harada, Y. The genetic structure of endangered indigenous populations of the amago salmon, Oncorhynchus masou ishikawae, in Japan. Conservation Genetics 8, 1163-1176 (2007).

15. Tamate, T. H. M. The relationship between the number of main dams and the coastal catch of masu salmon (Oncorhynchus masou) in Hokkaido: implications for river ecosystem conservation. Water Science $\mathbf{5 2}$ (2008).

16. Chen, J.-P. et al. Genetic analysis of four wild chum salmonOncorhynchus keta populations in China based on microsatellite markers. Environmental Biology of Fishes 73, 181-188, doi:10.1007/s10641-004-6114-0 (2005).

17. Lee, S., Bang, W. Y., Yang, H. S., Lee, D. S. \& Song, H. Y. Production of juvenile masu salmon (Oncorhynchus masou) from spermatogonia-derived sperm and oogonia-derived eggs via intraperitoneal transplantation of immature germ cells. Biochem Biophys Res Commun 535, 6-11, doi:10.1016/j.bbrc.2020.12.021 (2021).

18. Lever, C. Naturalized fishes of the world. (Naturalized fishes of the world, 1996).

19. Templeton, A. R. Coadaptation and outbreeding depression. Conservation Biology the Science of Scarcity Diversity (1986).

20. A, F. W. A., A, R. F. L., A, P. S. \& B, J. K. W. The problems with hybrids: setting conservation guidelines. Trends in Ecology Evolution 16, 613-622 (2001).

21. McGinnity, P. et al. Fitness reduction and potential extinction of wild populations of Atlantic salmon, Salmo salar, as a result of interactions with escaped farm salmon. Proc Biol Sci 270, 2443-2450, doi:10.1098/rspb.2003.2520 (2003).

22. Youngson, A. F. et al. Management of salmonid fisheries in the British Isles: towards a practical approach based on population genetics. Fisheries Research 62, 193-209 (2003).

23. Frankel, O. H. \& Soule, M. E. Conservation and evolution. (Cambridge University Press, 1981).

24. Hoffmann, A. A., Sgrò, C. \& Lawler, S. H. J. A. R. o. G. Ecological population genetics: the interface between genes and the environment. 29, 349 (1995).

25. Yu, J. N. et al. Population genetic structure and phylogeography of masu salmon (Oncorhynchus masou masou) inferred from mitochondrial and microsatellite DNA analyses. Zoolog Sci 27, 375-385, doi:10.2108/zsj.27.375 (2010).

26. Jiang, Z. F. et al. Growth characters of cultured juvenile Oncorhynchus masou masou. Journal of Fishery Sciences of China (2007).

27. Xie, Y. Freshwater fishes of northeast China. 296-300 (Liaoning Science and Technology Press, 2007).

28. Kimura, M. A simple method for estimating evolutionary rates of base substitutions through comparative studies of nucleotide sequences. Journal of Molecular Evolution 16, 111-120 (1980).

29. Oohara, I. \& Okazaki, T. Genetic relationship among three subspecies of Oncorhynchus masou determined by mitochondrial DNA sequence analysis. Zoolog Sci 13, 189-198, doi:10.2108/zsj.13.189 (1996).

30. Linsley \& Gorton, E. Methods and principles of systematic zoology. (Methods and principles of systematic zoology, 1953).

31. Commission, I. R. International Code of Zoological Nomenclature. (1999).

32. Kato, F. Lepidological Study on Sea-run Specimens of Oncorhynchus rhodurus. Japanese Journal of Ichthyology 25, 51-57 (2011).

33. Avise, J. C., Neigel, J. E. \& Arnold, J. Demographic influences on mitochondrial DNA lineage survivorship in animal populations. Journal of Molecular Evolution 20, 99-105 (1984). 
34. Rogers \& Harpending. Population growth makes waves in the distribution of pairwise genetic differences. Molecular Biology Evolution (1992).

35. Was, G. \& Bowen, B. W. Shallow population histories in deep evolutionary lineages of marine fishes: Insights from sardines and anchovies and lessons for conservation. Journal of Heredity, 415-426 (1998).

36. Kang, X. The Causes of the Decline of Salmon Resources in the Tumen River and Measures to Recover Modern Agricultural Technology No.684, 243-245, doi:10.3969/j.issn.1007-5739.2016.22.138 (2016).

37. Hsu, T.-H. et al. Use of microsatellite DNA and amplified fragment length polymorphism for Cherry salmon (Oncorhynchus masou) complex identification. Aquaculture Research 41, e316-e325, doi:10.1111/j.1365-2109.2010.02533.x (2010).

38. Noguchi, D., Ikeda, M., Nakajima, M. \& Taniguchi, N. Isolation and Characterization of Microsatellite DNA Markers for Population Genetics Study of Masu Salmon, Oncorhynchus masou masou. Journal of Heredity 107 (2002).

39. Oreilly, P. T., Hamilton, L. C., Mcconnell, S. K. \& Wright, J. M. Rapid analysis of genetic variation in Atlantic salmon (Salmo salar) by PCR multiplexing of dinucleotide and tetranucleotide microsatellites. Can.j.fish.aquat 53, 2292-2298 (1996).

40. Michael O'Connell, Roy G Danzmann, , Jean-Marie Cornuet, , Jonathan M Wright, \& , M. M. F. Differentiation of rainbow trout (Oncorhynchus mykiss) populations in Lake Ontario and the evaluation of the stepwise mutation and infinite allele mutation models using microsatellite variability. Canadian Journal of Fisheries Aquatic Sciences 54, 1391-1399 (1997).

\section{Tables}

Table 1: Characteristics of masou salmon microsatellite loci, PCR primer, repeat motifs, an annealing temperature and allele size ranges in this study.

\begin{tabular}{|c|c|c|c|c|c|c|}
\hline Loci & Primer sequence $\left(5^{\prime} 3^{\prime}\right)$ & Repeat & $\operatorname{Tm}\left({ }^{\circ} \mathrm{C}\right)$ & $\mathrm{MgCl} 2(\mathrm{mM})$ & Allele size (bp) & Reference \\
\hline \multirow[t]{2}{*}{ Omi17 } & F: GCCTAAGCATACAAGAAGGC & $(\mathrm{CA}) \mathrm{n}$ & 62 & 1 & 123 & AB105828 \\
\hline & R: TGGTTGACATCGAGTGGAAC & & & & & \\
\hline \multirow[t]{2}{*}{ Omi50 } & F: CTTAGAACCAACAAACGTGGG & $(\mathrm{CA}) \mathrm{n}$ & 62 & 2 & 154 & AB105834 \\
\hline & R: GCAGTGTCTTTGTGGCAAGA & & & & & \\
\hline \multirow[t]{2}{*}{ Omi57 } & F: GATCAGCCCCATGTGTGAC & $(\mathrm{CA}) \mathrm{n}$ & 62 & 1 & 133 & AB105835 \\
\hline & R: CGGGGTGAGTATGCTTGAAT & & & & & \\
\hline \multirow[t]{2}{*}{ Omi65 } & F: CCACTAGGGAGCCACACTGT & $(\mathrm{CA}) \mathrm{n}$ & 60 & 2 & 113 & AB105837 \\
\hline & R: CTGACAGCTCCATACTAGTGCG & & & & & \\
\hline \multirow[t]{2}{*}{ Omi70 } & F: TTCTTATGACCCGTTCCTGC & $(\mathrm{CA}) \mathrm{n}$ & 62 & 2 & 141 & AB105840 \\
\hline & R: CATCGCTTTCCTGATGCC & & & & & \\
\hline \multirow[t]{2}{*}{ Omi77 } & F: GTCAACACTGAGACGTCTGACA & $(\mathrm{CA}) \mathrm{n}$ & 62 & 1 & 106 & AB105841 \\
\hline & R: GTTCCTGAGTAGCTGGCAGC & & & & & \\
\hline \multirow[t]{2}{*}{ Omi87 } & F: CCAACTCCCGTATCCTCAGA & $(\mathrm{CA}) \mathrm{n}$ & 58 & 2 & 118 & AB213231 \\
\hline & R: TGCCTTTCAGAAGGTGGC & & & & & \\
\hline \multirow[t]{2}{*}{ Omi102 } & F: TTAACATAACGCACACAGAGGC & $(\mathrm{CA}) \mathrm{n}$ & 62 & 2 & 133 & AB105844 \\
\hline & R: TCACAAGACCAGAGACACGTG & & & & & \\
\hline \multirow[t]{2}{*}{ Omi109 } & F: AGAGGTAGTCTGGGAGATGGC & $(\mathrm{CA}) \mathrm{n}$ & 58 & 2 & 99 & AB105845 \\
\hline & R: CTTATTTGACCAACACGCGA & & & & & \\
\hline \multirow[t]{2}{*}{ Omi112 } & F: TTCCAGCAGTTTCGGGAG & $(\mathrm{CA}) \mathrm{n}$ & 60 & 2 & 101 & AB105847 \\
\hline & R: GATGGGCTGCTGACACAGTA & & & & & \\
\hline \multirow[t]{2}{*}{ Omi179 } & F: TTATCCTAGTGCCGGGTCTG & $(\mathrm{CA}) \mathrm{n}$ & 58 & 2 & 128 & AB105856 \\
\hline & R: ATGCAGCTTTTCAGTGGCTT & & & & & \\
\hline \multirow[t]{2}{*}{ Oma4my } & F: CTGCGCATGTGTAGCCTATG & * & 56 & 1 & 150 & Noguchi et al. (2003) \\
\hline & R: TCTTTAGAGGGGGTCATTAC & & & & & \\
\hline \multirow[t]{2}{*}{ Ssa197 } & F: GGGTTGAGTAGGGAGGCTTG & $(\mathrm{TA}) \mathrm{n}$ & 57 & 1 & 115 & O’Reilly et- al. (1996) \\
\hline & R: TGGCAGGGATTTGACATAAC & & & & & \\
\hline \multirow[t]{2}{*}{ Ssa293 } & F: TGGTTATTTGTTTCCAGAG & $(\mathrm{GT}) \mathrm{n}$ & 53 & 1 & 110 & O'Connell et al. (1997) \\
\hline & R: ATCAGATACACAGAGACGG & & & & & \\
\hline
\end{tabular}

* (GT)5C(TG)4TC(TG)3A(GTGA) 15. 
PCR, polymerase chain reaction.

Table 2: External characteristics $(M \pm S D)$, sex ratio and age composition of 2 masu salmon groups. $M \pm S D$ is the average value and its standard deviation.

\begin{tabular}{|c|c|c|c|}
\hline & & \multicolumn{2}{|l|}{ population } \\
\hline & & MJ salmon $(N=35)$ & JP salmon $(N=20)$ \\
\hline \multirow[t]{2}{*}{ Weight, $\mathrm{g}$} & Body weight & $112.81 \pm 10.69$ & $49.51 \pm 7.25$ \\
\hline & without internal organs & $93.57 \pm 8.90$ & $41.47 \pm 5.68$ \\
\hline \multirow[t]{2}{*}{ Length, cm } & Standard length & $19.63 \pm 0.59$ & $16.46 \pm 0.52$ \\
\hline & Fork length & $18.64 \pm 0.56$ & $15.19 \pm 0.52$ \\
\hline \multicolumn{2}{|c|}{ 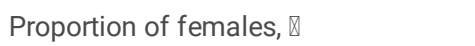 } & 11 & 75 \\
\hline \multirow[t]{3}{*}{ 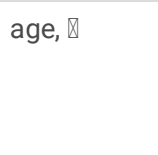 } & 1 & 20 & 20 \\
\hline & 2 & 60 & 50 \\
\hline & 3 & 20 & 30 \\
\hline
\end{tabular}

Table3: Coefficient of difference of proportional traits between two groups of masu Salmon.

\begin{tabular}{|llll|}
\hline proportional traits & MJ salmon & JP salmon & C.D \\
\hline $\mathrm{Fl} / \mathrm{SI}$ & $1.11 \pm 0.02$ & $1.08 \pm 0.08$ & 0.376 \\
\hline $\mathrm{Bd} / \mathrm{SI}$ & $0.31 \pm 0.02$ & $0.24 \pm 0.02$ & 1.658 \\
\hline $\mathrm{BW} / \mathrm{SI}$ & $0.16 \pm 0.02$ & $0.13 \pm 0.02$ & 1.134 \\
\hline $\mathrm{BI} / \mathrm{SI}$ & $1.17 \pm 0.02$ & $1.16 \pm 0.03$ & 0.132 \\
\hline $\mathrm{HI} / \mathrm{SI}$ & $0.24 \pm 0.01$ & $0.25 \pm 0.01$ & 0.321 \\
\hline $\mathrm{SNI} / \mathrm{SI}$ & $0.07 \pm 0.01$ & $0.07 \pm 0.01$ & 0.018 \\
\hline $\mathrm{Ed} / \mathrm{SI}$ & $0.05 \pm 0.01$ & $0.05 \pm 0$ & 0.811 \\
\hline $\mathrm{HEl} / \mathrm{SI}$ & $0.13 \pm 0.01$ & $0.13 \pm 0.01$ & 0.009 \\
\hline $\mathrm{BAl} / \mathrm{SI}$ & $0.73 \pm 0.02$ & $0.71 \pm 0.03$ & 0.3495 \\
\hline $\mathrm{CPI} / \mathrm{SI}$ & $0.28 \pm 0.01$ & $0.16 \pm 0.03$ & 2.902 \\
\hline $\mathrm{CPd} / \mathrm{SI}$ & $0.1 \pm 0.01$ & $0.09 \pm 0.01$ & 0.556 \\
\hline
\end{tabular}

Table4: Variable nucleotide positions in haplotypes among several subspecies of the Oncorhynchus masou. 


\begin{tabular}{|c|c|c|c|c|c|c|c|c|c|c|c|c|c|c|c|c|c|}
\hline & \multirow[b]{4}{*}{ Haplotype } & \multicolumn{15}{|c|}{ Relative nucleotide position in compared sequences } & \multirow{3}{*}{$\begin{array}{l}6 \\
7\end{array}$} \\
\hline & & \multicolumn{4}{|l|}{ Number } & \multirow{2}{*}{$\begin{array}{l}1 \\
1\end{array}$} & \multirow{2}{*}{$\begin{array}{l}1 \\
7\end{array}$} & \multirow{2}{*}{$\begin{array}{l}1 \\
8\end{array}$} & \multirow{2}{*}{$\begin{array}{l}2 \\
0\end{array}$} & \multirow{2}{*}{$\begin{array}{l}2 \\
1\end{array}$} & \multirow{2}{*}{$\begin{array}{l}2 \\
9\end{array}$} & \multirow{2}{*}{$\begin{array}{l}3 \\
2\end{array}$} & \multirow{2}{*}{$\begin{array}{l}4 \\
0\end{array}$} & \multirow{2}{*}{$\begin{array}{l}5 \\
6\end{array}$} & \multirow{2}{*}{$\begin{array}{l}5 \\
9\end{array}$} & \multirow{2}{*}{$\begin{array}{l}6 \\
2\end{array}$} & \\
\hline & & of & 1 & 4 & 5 & & & & & & & & & & & & \\
\hline Sample name $(*)$ & & haplotype & 4 & 1 & 9 & 6 & 0 & 5 & 0 & 5 & 9 & 5 & 7 & 2 & 9 & 6 & 4 \\
\hline \multirow[t]{3}{*}{ O. masou masou } & a & 1 & C & G & A & G & $\mathrm{T}$ & $\mathrm{T}$ & $\mathrm{C}$ & A & A & C & C & G & $\mathrm{T}$ & G & C \\
\hline & $\mathrm{b}$ & 2 & . & . & . & A & . & . & . & . & . & . & $\mathrm{T}$ & $\mathrm{T}$ & . & . & - \\
\hline & c & 1 & $\mathrm{~T}$ & A & . & A & . & . & . & $\mathrm{T}$ & . & . & $\mathrm{T}$ & $\mathrm{T}$ & . & . & - \\
\hline O. masouformosanus & $d$ & 1 & . & . & . & A & . & . & . & . & . & . & . & $\mathrm{T}$ & $A$ & . & . \\
\hline O. masouishikawae & $\mathrm{e}$ & 2 & . & . & . & A & . & $\mathrm{C}$ & . & . & . & . & . & $\mathrm{T}$ & . & . & . \\
\hline \multirow[t]{2}{*}{ O. masou biwa } & $f$ & 1 & . & . & G & A & . & . & $\mathrm{T}$ & . & . & . & $\mathrm{T}$ & $\mathrm{T}$ & . & A & - \\
\hline & $\mathrm{g}$ & 1 & $\mathrm{~T}$ & . & G & A & . & . & $\mathrm{T}$ & . & . & G & $\mathrm{T}$ & $\mathrm{T}$ & . & A & - \\
\hline \multirow[t]{2}{*}{ JP } & $b$ & 3 & . & . & . & A & . & . & . & . & . & . & $\mathrm{T}$ & $\mathrm{T}$ & . & . & - \\
\hline & $\mathrm{h}$ & 7 & . & . & . & A & $\mathrm{C}$ & & & . & & . & $\mathrm{T}$ & $\mathrm{T}$ & . & . & $\mathrm{T}$ \\
\hline \multirow[t]{5}{*}{$\mathrm{MJ}$} & $\mathrm{i}$ & 9 & . & . & . & A & . & . & . & . & . & . & . & $\mathrm{T}$ & . & . & $\mathrm{T}$ \\
\hline & $\mathrm{b}$ & 15 & . & . & . & A & . & & & . & . & . & $\mathrm{T}$ & $\mathrm{T}$ & . & . & - \\
\hline & j & 7 & . & . & . & A & . & . & . & . & $\mathrm{G}$ & . & . & $\mathrm{T}$ & . & . & $\mathrm{T}$ \\
\hline & $\mathrm{k}$ & 1 & . & . & . & . & . & . & . & . & . & . & . & $\mathrm{T}$ & . & . & $\mathrm{T}$ \\
\hline & 1 & 3 & . & . & . & . & . & . & . & . & G & . & . & $\mathrm{T}$ & . & . & $\mathrm{T}$ \\
\hline codon position (**) & & & 3 & 3 & 3 & 3 & 3 & 3 & 3 & 3 & 3 & 2 & 3 & 2 & 3 & 3 & 3 \\
\hline 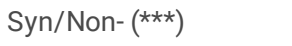 & & & $S$ & $S$ & $S$ & $S$ & $S$ & $S$ & $S$ & $S$ & $S$ & $\mathrm{~N}$ & $S$ & $\mathrm{~N}$ & $S$ & $S$ & $\mathrm{~S}$ \\
\hline
\end{tabular}

$\left.{ }^{\star}\right)$ Sample name: MJ, wild masou salmon from the Mijiang River.

$\left.{ }^{(\star \star}\right)$ Codon position: first (1), second (2) or third (3) codon position for protein coding regions.

$\left.{ }^{(\star \star \star}\right)$ Syn/Non-: Synonymous or non-synonymous substitution of protein coding sequences.

Table5: Haplotype diversity (Hd) and Nucleotide Diversity $(\pi)$ of COI gene in MJ and JP salmon population.

\begin{tabular}{|llll|}
\hline population & $\mathrm{n}$ & $\mathrm{Hd}$ & $\pi$ \\
$\mathrm{MJ}$ & 35 & $0.817 \pm 0.025$ & $0.00243 \pm 0.00022$ \\
$\mathrm{JP}$ & 20 & $0.268 \pm 0.113$ & $0.00045 \pm 0.00019$ \\
\hline
\end{tabular}

Table6: Genetic distance matrix for the haplotypes. For each pair of haplotypes, the percentage (\%) of genetic distance is given below the diagonal, and its standard deviation is given above the diagonal. These values were calculated using Kimura's two parameter method for correcting multiple-hits. 


\begin{tabular}{|c|c|c|c|c|c|c|c|c|c|c|c|c|c|}
\hline & \multirow[t]{2}{*}{ haplotypes } & \multicolumn{3}{|c|}{ Cherry salmon } & \multirow{2}{*}{$\begin{array}{l}\text { Formosa } \\
\text { landlocked } \\
\text { salmon } \\
\text { d }\end{array}$} & \multirow{2}{*}{$\begin{array}{l}\text { Satsukimasu } \\
\text { salmon } \\
\text { e }\end{array}$} & \multicolumn{2}{|c|}{ Biwa salmon } & \multicolumn{2}{|c|}{ JP salmon } & \multicolumn{3}{|c|}{ MJ salmon } \\
\hline & & a & $b$ & c & & & $f$ & g & $\mathrm{b}$ & $\mathrm{h}$ & i & $\mathrm{b}$ & j \\
\hline \multirow{3}{*}{$\begin{array}{l}\text { Cherry } \\
\text { salmon }\end{array}$} & a & - & 0.0027 & 0.0038 & 0.0026 & 0.0026 & 0.0037 & 0.0043 & 0.0031 & 0.0030 & 0.0022 & 0.0031 & C \\
\hline & $b$ & 0.0047 & - & 0.0026 & 0.0021 & 0.0022 & 0.0027 & 0.0034 & 0.0015 & 0.0016 & 0.0015 & 0.0015 & C \\
\hline & c & 0.0095 & 0.0047 & - & 0.0033 & 0.0033 & 0.0037 & 0.0037 & 0.0021 & 0.0031 & 0.0030 & 0.0021 & C \\
\hline $\begin{array}{l}\text { Formosa } \\
\text { landlocked } \\
\text { salmon }\end{array}$ & $d$ & 0.0047 & 0.0032 & 0.0079 & - & 0.0023 & 0.0035 & 0.0041 & 0.0026 & 0.0026 & 0.0015 & 0.0026 & C \\
\hline $\begin{array}{l}\text { Satsukimasu } \\
\text { salmon }\end{array}$ & e & 0.0047 & 0.0032 & 0.0079 & 0.0032 & - & 0.0036 & 0.0042 & 0.0027 & 0.0026 & 0.0015 & 0.0027 & C \\
\hline \multirow[t]{2}{*}{ Biwa salmon } & $f$ & 0.0095 & 0.0048 & 0.0095 & 0.0079 & 0.0079 & - & 0.0022 & 0.0031 & 0.0031 & 0.0031 & 0.0031 & C \\
\hline & $\mathrm{g}$ & 0.0127 & 0.0079 & 0.0095 & 0.0111 & 0.0111 & 0.0032 & - & 0.0037 & 0.0037 & 0.0038 & 0.0037 & C \\
\hline \multirow[t]{2}{*}{ JP salmon } & $b$ & 0.0063 & 0.0016 & 0.0032 & 0.0047 & 0.0048 & 0.0063 & 0.0095 & - & 0.0022 & 0.0021 & 0.0000 & C \\
\hline & $\mathrm{h}$ & 0.0063 & 0.0016 & 0.0063 & 0.0047 & 0.0048 & 0.0063 & 0.0095 & 0.0032 & - & 0.0021 & 0.0022 & C \\
\hline \multirow[t]{5}{*}{ MJ salmon } & i & 0.0032 & 0.0016 & 0.0063 & 0.0016 & 0.0016 & 0.0063 & 0.0095 & 0.0032 & 0.0032 & - & 0.0021 & C \\
\hline & $b$ & 0.0063 & 0.0016 & 0.0032 & 0.0047 & 0.0048 & 0.0063 & 0.0095 & 0.0000 & 0.0032 & 0.0032 & - & C \\
\hline & j & 0.0047 & 0.0032 & 0.0079 & 0.0032 & 0.0032 & 0.0079 & 0.0111 & 0.0048 & 0.0048 & 0.0016 & 0.0048 & - \\
\hline & $\mathrm{k}$ & 0.0016 & 0.0032 & 0.0079 & 0.0032 & 0.0032 & 0.0079 & 0.0111 & 0.0048 & 0.0048 & 0.0016 & 0.0048 & C \\
\hline & I & 0.0032 & 0.0048 & 0.0095 & 0.0047 & 0.0048 & 0.0096 & 0.0128 & 0.0063 & 0.0063 & 0.0032 & 0.0063 & C \\
\hline
\end{tabular}

Table7: Variation at fourteen microsatellite loci in Mijaing masou salmon population. $N$, number of individuals; $N A$, number of alleles; $A$, allelic richness; $h e$, expected heterozygosity; ho, observed heterozygosity; $P$, estimate of probability of deviation from Hardy-Weinberg equilibrium; ${ }^{*}$, significant departure from Hardy-Weinberg equilibrium (p 10.05$) ;{ }^{* *}$, significant departure from Hardy-Weinberg equilibrium (p[0.01).

\begin{tabular}{|c|c|c|c|c|c|}
\hline \multirow[t]{2}{*}{ loci } & \multicolumn{5}{|c|}{ Mijiang $(N=35)$} \\
\hline & $N A$ & $A r$ & he & ho & $P$ \\
\hline Omi17 & 8 & 7.31 & 0.6161 & 0.2571 & $0.0000^{\star *}$ \\
\hline Omi50 & 16 & 13.64 & 0.9014 & 0.7429 & $0.0000^{\star *}$ \\
\hline Omi57 & 14 & 12.44 & 0.8832 & 0.4571 & $0.0000^{\star \star}$ \\
\hline Omi65 & 6 & 5.38 & 0.7155 & 0.8286 & 0.1980 \\
\hline Omi70 & 4 & 3.93 & 0.6364 & 0.6000 & 0.3959 \\
\hline Omi77 & 18 & 14.13 & 0.9072 & 0.3143 & $0.0000^{\star *}$ \\
\hline Omi87 & 9 & 7.57 & 0.8012 & 0.7429 & 0.2454 \\
\hline Omi102 & 15 & 12.10 & 0.8625 & 0.7429 & $0.0173^{*}$ \\
\hline Omi109 & 13 & 10.38 & 0.759 & 0.5714 & $0.0076^{\star *}$ \\
\hline Omi112 & 7 & 6.56 & 0.7408 & 0.8286 & 0.7658 \\
\hline Omi179 & 11 & 9.83 & 0.8166 & 0.6286 & $0.0180^{*}$ \\
\hline Oma4my & 5 & 4.90 & 0.6629 & 0.5143 & 0.0649 \\
\hline Ssa197 & 15 & 12.27 & 0.8899 & 0.8286 & $0.0000^{\star *}$ \\
\hline Ssa293 & 13 & 10.86 & 0.8153 & 0.4286 & $0.0000^{\star *}$ \\
\hline Mean & 11.0714 & 9.38 & 0.7863 & 0.6061 & - \\
\hline
\end{tabular}

Table8: Analysis of molecular (AMOVA) among 2 levels of the population hierarchy for COI and microsatellite markers. 


\begin{tabular}{|lllll|}
\hline Hierarchical & COI & \multicolumn{3}{l|}{ Microsatellites } \\
\cline { 2 - 5 } structure & Variance & $\mathrm{P}$ & Variance & $\mathrm{P}$ \\
\hline Among populations & $3.192(39.0 \%)$ & 0.000 & $0.135(2.5 \%)$ & 0.000 \\
\hline Within populations & $4.987(61.0 \%)$ & 0.000 & $5.392(97.5 \%)$ & 0.000 \\
\hline
\end{tabular}

Table9: $F_{I S}, F_{S T}$ and $\mathrm{Nm}$ value among 14 microsatellite loci in 2 masu salmon groups.

\begin{tabular}{|lllllll|}
\hline Ioci & \multicolumn{2}{l}{ MJ salmon } & & \multicolumn{3}{l|}{ JP salmon } \\
& $\mathrm{F}_{\text {IS }}$ & $\mathrm{F}_{\mathrm{ST}}$ & $\mathrm{Nm}$ & $\mathrm{F}_{\text {IS }}$ & $\mathrm{F}_{\mathrm{ST}}$ & $\mathrm{Nm}$ \\
\hline Omi17 & 0.5778 & 0.0275 & 8.8409 & 0.2670 & 0.0398 & 12.0628 \\
\hline Omi50 & 0.1533 & 0.0399 & 6.0157 & 0.2375 & -0.0326 & -15.8374 \\
\hline Omi57 & 0.4845 & 0.0043 & 57.890 & 0.0557 & 0.0397 & 12.09446 \\
\hline Omi65 & -0.2434 & 0.0897 & 2.5371 & 0.2010 & -0.1282 & -4.40016 \\
\hline Omi70 & 0.0203 & 0.0525 & 4.5119 & 0.0943 & -0.0930 & -5.87634 \\
\hline Omi77 & 0.6334 & 0.0863 & 2.6469 & 0.7332 & -0.0505 & -10.401 \\
\hline Omi87 & 0.0243 & 0.0689 & 3.3784 & 0.0896 & 0.0054 & 92.09259 \\
\hline Omi102 & 0.1175 & 0.0357 & 6.7528 & 0.2715 & -0.0199 & -25.6256 \\
\hline Omi109 & 0.2448 & 0.0092 & 26.924 & 0.1869 & -0.0553 & -9.54159 \\
\hline Omi112 & -0.1341 & 0.0166 & 14.810 & 0.1197 & -0.0880 & -6.18182 \\
\hline Omi179 & 0.2012 & 0.0539 & 4.3882 & 0.2829 & -0.0315 & -16.373 \\
\hline Oma4my & 0.1936 & 0.056 & 4.2143 & 0.0289 & 0.1186 & 3.715852 \\
\hline Ssa197 & 0.0287 & 0.0577 & 4.0828 & -0.0858 & -0.0189 & -26.955 \\
\hline Ssa293 & 0.4074 & 0.1576 & 1.3363 & 0.5478 & -0.0545 & -9.67431 \\
\hline Mean & 0.1995 & 0.0540 & 10.595 & 0.2294 & -0.0232 & -22.0517 \\
\hline
\end{tabular}

Table10: Estimated pairwise FST (CO1 data, below diagonal; microsatellite data, above diagonal) values of two populations. * means significant.

\begin{tabular}{|lll|}
\hline & MJ & JP \\
\hline MJ & - & $0.024^{*}$ \\
\hline JP & $0.375^{*}$ & - \\
\hline
\end{tabular}

\section{Figures}




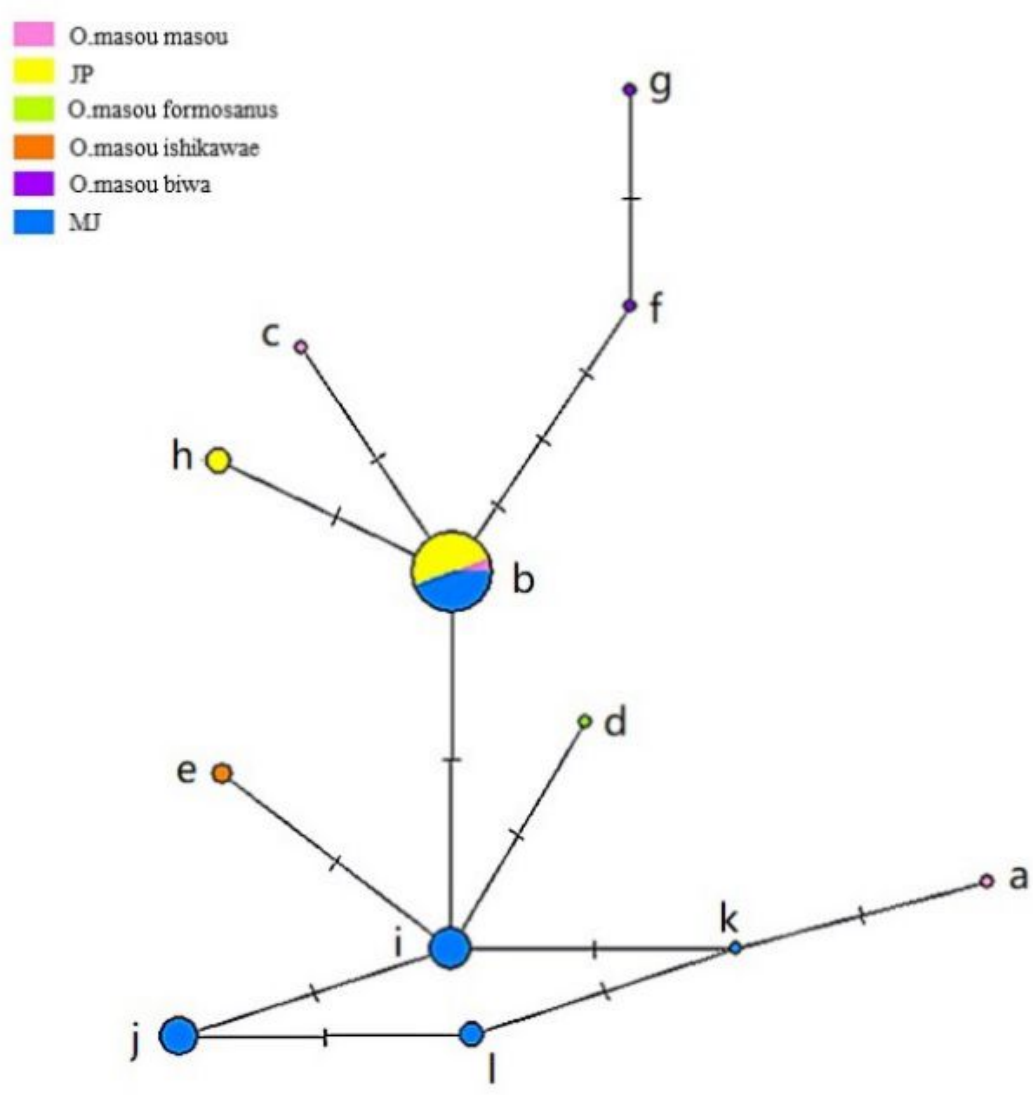

Figure 1

Haplotypes network among Masusubspecies complex.The haplotypes "a" to "I" correspond to those shown in Table 4: Cherry salmon corresponds to haplotypes "a", "b" and "c"; Farmed Masu salmon corresponds to haplotypes "b" and "h"; Formosa landlocked salmon corresponds to the haplotype "d";Satsukimasu salmoncorresponds to the haplotype "e"; Biwa salmon corresponds to the haplotype "f" and "g"; and Masu salmon from Mijaing River corresponds to the haplotype "b" and "i" to "I ". 


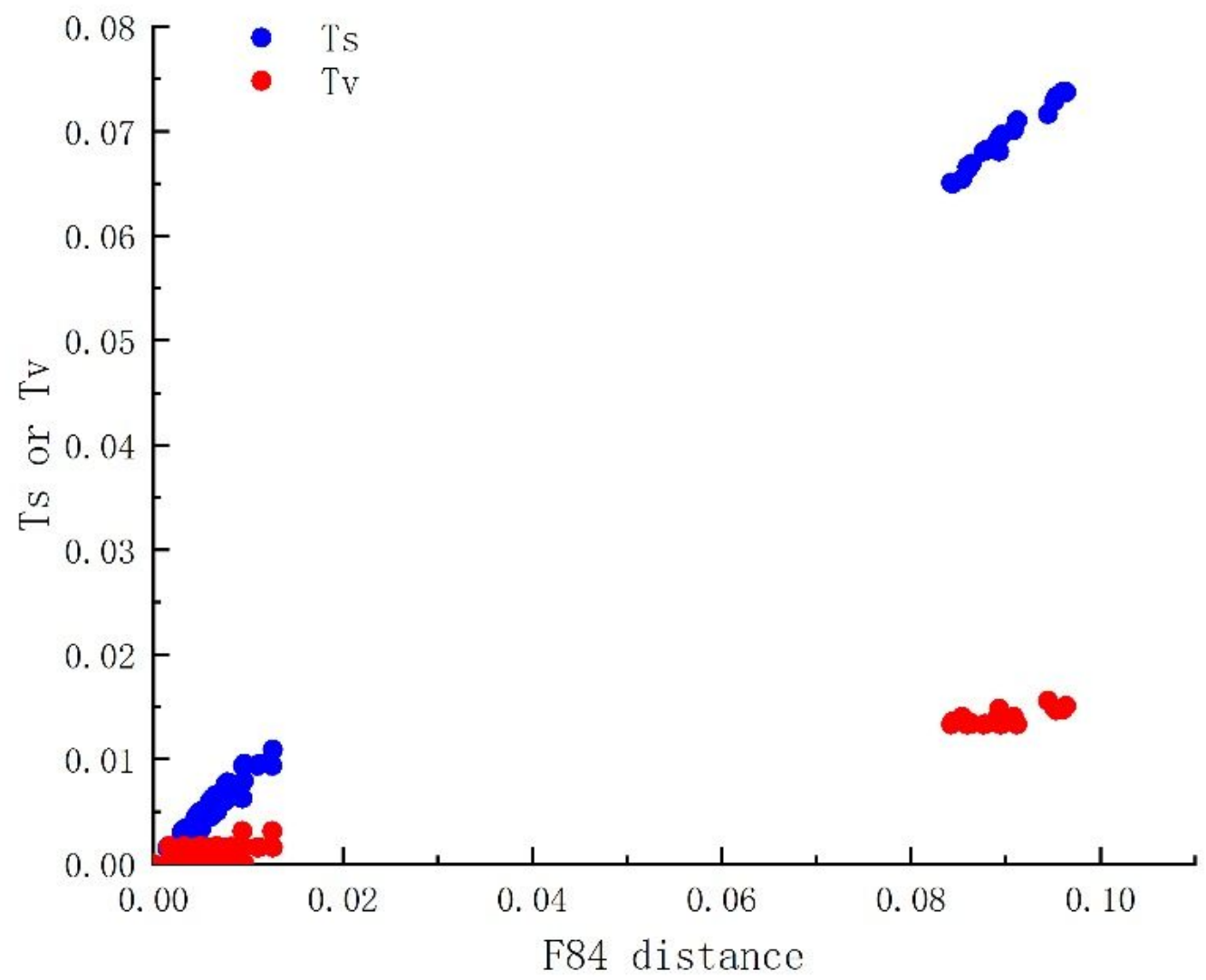

Figure 2

The base saturation analysis of $\mathrm{COI}$ sequence among masu subspecies complex. The neighbor-joining trees for masu Salmon from Mijiang and farm, cherry salmon, satsukimasu salmon, formosa landlocked salmon and biwa salmon, based on COI gene of data. 


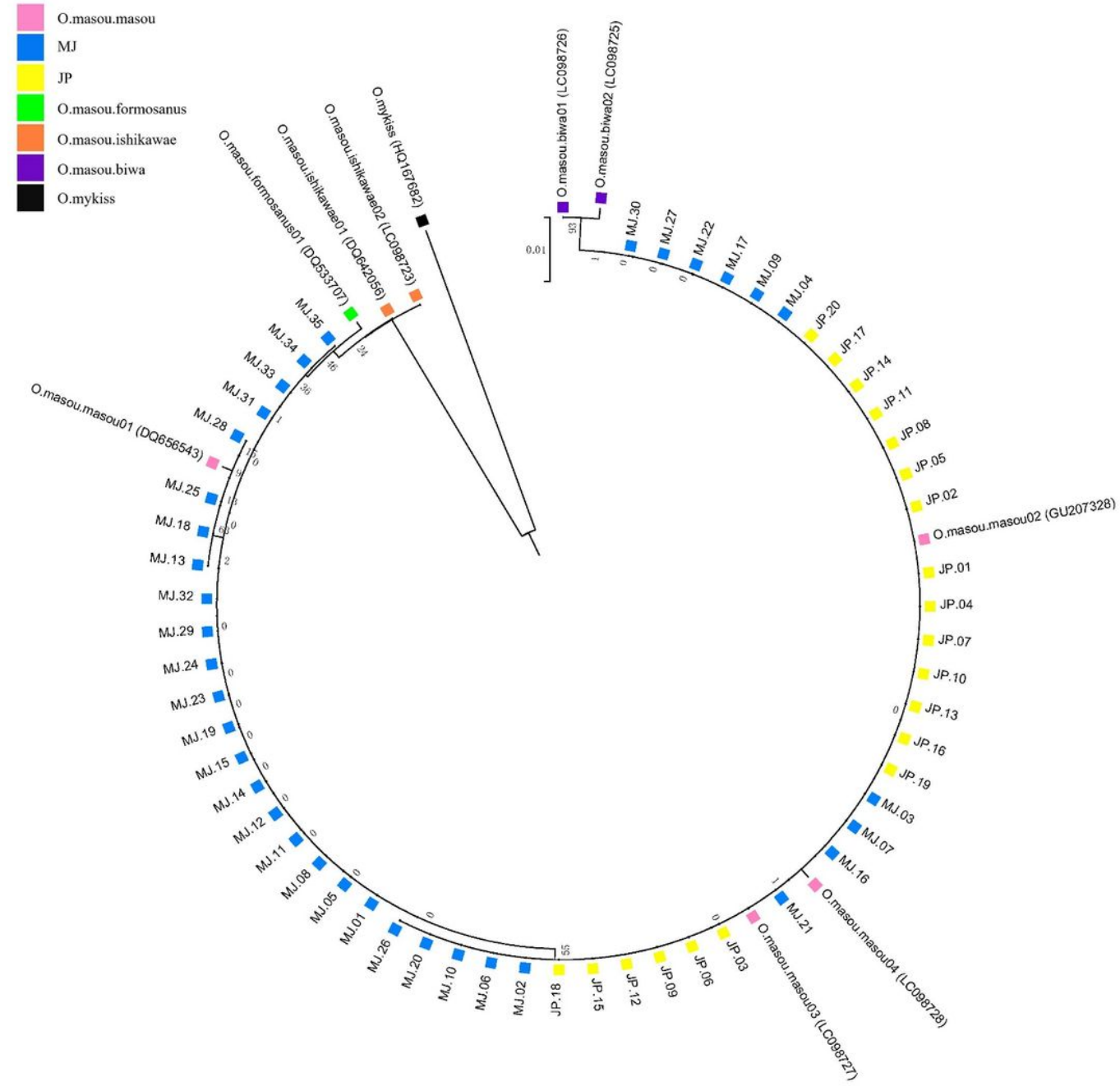

\section{Figure 3}

The neighbor-joining trees for masu salmon from Mijiang and farm, cherry salmon, satsukimasu salmon, formosa landlocked salmon and biwa salmon, based on COI gene of data. 